\title{
Cytokine signatures of human whole blood for monitoring immunosuppression
}

\author{
YI HE, YUWEI LUO, XIAOBIN LAO, LIPING TAN, ERWEI SUN
}

Department of Rheumatology and Immunology and Experimental Medical Center, The Third Affiliated Hospital, Southern Medical University; Institute of Clinical Immunology, Academy of Orthopedics, Guangzhou Province, PR China

\begin{abstract}
How to evaluate status of the immune system is extremely critical for clinical immunosuppressive treatment. In this study, we tested the secretion of cytokines in undiluted whole blood samples stimulated with Phorbol 12-myristate 13-acetate (PMA) and ionomycin (IONO), and compared the effects of dexamethasone (DEX), cyclosporine A (CsA) or mycophenolic acid (MPA), either alone or in combination, on cytokine profiles. The results showed that both DEX and CsA dose-dependently inhibited the production of eleven cytokines: interleukin (IL)-2, IL-4, IL-5, IL-6, IL-13,IL-17, interferon $\gamma(I F N-\gamma)$, tumor necrosis factor $\alpha(T N F-\alpha)$, granulocyte-macrophage colony-stimulating factor (GM-CSF) and granulocyte colony-stimulating factor $(G-C S F)$. Unexpectedly, MPA showed no obvious influences except for the mild inhibition on GM-CSF production. In combination treatment, cytokine profiles reflect not only the synergistic effects among drugs, but also the specific effect of the individual drug. Thus, the effects of different immunosuppressants could be reflected through their specific cytokine signatures, which can be applied to maximize immunosuppressive effects, while to minimize risk of infections and help physicians to reasonably apply immunosuppressants.
\end{abstract}

Key words: immune status, autoimmune immune diseases, rejection, infection, cytokine, immunosuppression.

(Centr Eur J Immunol 2014; 39 (3): 271-278)

\section{Introduction}

Although immunosuppressants have been applied for a half century in patients with autoimmune diseases, allergic disorders or transplant rejection, there are currently no reliable methods to evaluate how much the immune system is suppressed [1, 2]. Excessive immunosuppression destroys the immune system and leads to severe, even fatal, infections, whereas insufficient immunosuppression does not effectively block progression of autoimmune diseases, allergic disorders or graft rejections. In fact, efforts have been taken for decades in order to define functions of immune cells of patients. However, except for the blood immune cell counts, lymphocyte proliferation, cytotoxic T lymphocyte (CTL), serum antibody titers, etc. [3-5], methods able to reliably monitor clinical immunological functions are still lacking. Consequently, physicians have to depend on other non-immunological examinations, such as symptoms or signs, ultrasound or CT scan, biopsy or blood concentrations of drugs to adjust the type and dose of immunosuppressants.

Cytokines are important players during the functioning of immune cells, in both intracellular signal transduction and intercellular communications [6-8]. Luminex xMAP technology makes it possible to simultaneously detect up to a hundred of cytokines in a single $12 \mu \mathrm{l}$ sample [9-11]. The technique makes us believe that the detection of multiple cytokine profiles of whole blood with a short-term in vitro stimulation may be one of best candidate methods for monitoring clinical immune function [12]. In this study, we investigated profiles of seventeen cytokines in undiluted whole blood samples stimulated in vitro with Phorbol 12-myristate 13-acetate (PMA) and ionomycin (IONO) (PMA/IONO) for $6 \mathrm{~h}$ and compared the effects of different immunosuppressants on immunity. The results showed that different immunosuppressants displayed distinctive effects on cytokine secretion that may be used to evaluate the function of immune cells and to determine the specific impact of an individual immunosuppressant. We believe that this novel technique is able to help physicians to decide whether the immune system is undesirably inhibited and which immunosuppressant should be adjusted to maximize the therapeutic effects while to minimize the risk of infection in patients with autoimmune diseases, allergic disorders or transplant rejection [13-17].

Correspondence: Erwei Sun, Department of Rheumatology and Immunology, Experimental Medical Center, Third Affiliated Hospital, Southern Medical University, Guangzhou, China, 183 Zhongshan Ave, Guangzhou 510630, China, tel. +86-20-627-84421, fax +86-20-616-42703, e-mail: ewsun@263.net 


\section{Material and methods}

\section{Subjects}

Peripheral venous blood samples were obtained with informed consent from twenty three healthy volunteers at 20-30 years of age and collected in vacuum tubes containing dried lithium heparin. The blood samples were added into 96-well plate for in vitro stimulation.

\section{Stimulating reagents and immunosuppressive drugs}

PMA (Sigma, USA), IONO (Sigma, USA), and phytohemagglutinin (PHA) (Sigma, USA) were used to stimulate immune cells. PMA and PHA were diluted with PBS and IONO was diluted with RPMI-1640. Three immunosuppressive drugs, dexamethasone (DEX) (Sigma, USA), cyclosporine A (CsA) (Huadong Pharmaceutical Co., Ltd, China) and mycophenolic acid (MPA) (Alexis, USA) were diluted in PBS and stored at $4^{\circ} \mathrm{C}$. In this in vitro study, we chose DEX, CsA and MPA as testing drugs because they are the immunosuppressants frequently used in clinical settings. Although CsA is metabolized in the liver if it is administrated orally, most of CsA is present in the blood, and blood CsA concentration is correlated to its clinical efficacy. Dexamethasone is usually used in an injection form. Mycophenolic acid is the bioactive metabolite of its original drug, Mycophenolate mofetil (MMF). And a previous study indicated that DEX, CsA and MPA can be used directly for the study in vitro [18-20]. Bio-Plex human cytokine multi-plex kits were purchased from Bio-Rad Laboratories (CA, USA).

\section{Whole blood stimulation}

Heparinized undiluted whole blood $(200 \mu \mathrm{l})$ was co-cultured with or without immunosuppressive drugs for $6 \mathrm{~h}$ and then stimulated with PMA/IONO or PHA for $6 \mathrm{~h}$ at $37^{\circ} \mathrm{C}$ with $5 \% \mathrm{CO}_{2}$. Then, the blood was centrifuged, and supernatants collected and stored at $-20^{\circ} \mathrm{C}$.

\section{Cytokine detection by the multi-plex technology}

Seventeen cytokines including interleukin (IL)-1 $\beta$, IL-2, IL-4, IL-5, IL-6, IL-7, IL-8, IL-10, IL-12, IL-13, IL-17, interferon $\gamma$ (IFN- $\gamma$ ), tumor necrosis factor $\alpha$ (TNF- $\alpha$ ), granulocyte colony-stimulating factor (G-CSF), granulocyte-macrophage colony-stimulating factor (GMCSF), MCP-1 and MIP-1 $\beta$ were detected simultaneously with Bio-Plex kit (Bio-Rad Laboratories, USA) as previously described and the data analyzed with the Bio-Plex manager software (version 4.0) [12].

\section{Data analyses}

The results were statistically analyzed using one-way ANOVA with SPSS 10.0 software. Newman-Keuls analysis was used to compare the differences between groups.

\section{Results}

\section{In vitro induction of cytokines in undiluted whole blood stimulated with PMA/IONO}

Although peripheral blood mononuclear cells (PBMCs) or blood samples diluted with complete culture medium have been frequently used in experimental and clinical studies, we believe that undiluted whole blood may be best for evaluating immune functions in patients with immunosuppressive treatments. The preparation procedures for PBMCs or diluted blood not only elongate the detection time, but also, more importantly, artificially alter the microenvironment necessary for the function of immune cells, either by washing out some essential factors, or by introducing artificial factors contained in fetal calf serum [21, 22]. Previously, we tested the effect of PHA, lipopolysaccharides (LPS) and concanavalin A (ConA) on the production of cytokine profiles, and found that PHA was the best among them [12]. As a $12 \mathrm{~h}$ stimulation period with PHA was essential for most cytokines to reach their plateau level, we tried to find more powerful stimuli that can boost cytokine production with even shorter-term stimulation. It has been known that PMA/IONO bypasses the membrane receptors by directly activating protein kinase $\mathrm{C}$ (PKC) as well as increasing intracellular calcium concentration, so that they synergistically stimulate lymphocytes to secret a large amount of cytokines within 4-6 h [23]. To verify that in human undiluted whole blood, we first tested the effect of different combinations of PMA $(0.025-0.1 \mu \mathrm{g} / \mathrm{ml})$ and IONO $(0.75-1.5 \mu \mathrm{g} / \mathrm{ml})$ on IL-2 production. The results showed that treatment of whole blood with PMA $(0.1 \mu \mathrm{g} / \mathrm{ml})$ and IONO $(1.5 \mu \mathrm{g} / \mathrm{ml})$ for $6 \mathrm{~h}$ greatly enhanced IL-2 production that was 10 times more than that stimulated with PHA $(10 \mu \mathrm{g} / \mathrm{ml})$ (data not shown). Then, we continued to test the effect of higher concentrations of PMA $(0.1-0.25 \mu \mathrm{g} / \mathrm{ml})$ and IONO (1.5-4 $\mu \mathrm{g} / \mathrm{ml})$ on the production of the above mentioned seventeen cytokines. The results showed that the combination of PMA $(0.15 \mu \mathrm{g} / \mathrm{ml})$ and IONO $(2.5 \mu \mathrm{g} / \mathrm{ml})$ most strongly stimulated the production of IL-4, IL-5, IL-6, IL-10, IL-13, IL-17, IFN- $\gamma$, TNF- $\alpha$, GM-CSF and G-CSF, although a higher concentration of PMA $(0.25 \mu \mathrm{g} / \mathrm{ml})$ and IONO ( $4 \mu \mathrm{g} / \mathrm{ml}$ ) might be even stronger for IL-2 production (data not shown). However, for the other six cytokines such as IL-1 $\beta$, IL-7, IL-8, IL-12, MCP-1 and MIP-1 $\beta$, PMA $(0.15 \mu \mathrm{g} / \mathrm{ml})$ and IONO $(2.5 \mu \mathrm{g} / \mathrm{ml})$ were not optimal for stimulation. Accordingly, we decided to stimulate undiluted whole blood samples with PMA $(0.15 \mu \mathrm{g} / \mathrm{ml})$ and IONO $(2.5 \mu \mathrm{g} / \mathrm{ml})$ and analyze eleven cytokines including IL-2, IL-4, IL-5, IL-6, IL-10, IL-13, IL-17, IFN- $\gamma$, TNF- $\alpha$, GM-CSF and G-CSF. Therefore, we determined to stimulate undiluted whole blood with PMA $(0.15 \mu \mathrm{g} / \mathrm{ml})$ and IONO $(2.5 \mu \mathrm{g} / \mathrm{ml})$ for $6 \mathrm{~h}$ in the following experiments. 


\section{Immunosuppressants distinctively influence cytokine profiles}

In order to know whether different immunosuppressants have distinctive effects on cytokine profiles, we set to test the effects of several clinically applied immunosuppressants, including DEX, CsA and MPA. To this end, whole blood were firstly co-cultured with different immunosuppressants for $6 \mathrm{~h}$, stimulated with PMA $(0.15 \mu \mathrm{g} / \mathrm{ml})$ and IONO $(2.5 \mu \mathrm{g} / \mathrm{ml})$ for another $6 \mathrm{~h}$ and detected for supernatant cytokines. As predicated, DEX dose-dependently inhibited the secretion of ten cytokines including IL-2, IL-4, IL-5, IL-6, IL-13, IL-17, IFN- $\gamma$, TNF- $\alpha$, GM-CSF and G-CSF, but did not influence the secretion of IL-10 (Fig. 1). It also seems that Th2 cytokines IL-4, IL-5 and IL-13 were more sensitive to DEX treatment. Dexamethasone reached its highest inhibitory activity at the concentration of $1 \mu \mathrm{g} / \mathrm{ml}$, while a 10 times higher concentration $(10 \mu \mathrm{g} / \mathrm{ml})$ resulted in no further inhibition. On the other hand, CsA dose-dependently inhibited all the eleven cytokines, including IL-2, IL-4, IL-5, IL-6, IL-10, IL-13, IL-17, IFN- $\gamma$, TNF- $\alpha$, GM-CSF and G-CSF (Fig. 2). It is worth mentioning that two DEX less sensitive cytokines,
IL-10 and G-CSF, were dramatically inhibited by CsA, indicating that cytokine profiles are immunosuppressant specific (Fig. 2). In contrast to DEX and CsA, MPA as high as $30 \mu \mathrm{g} / \mathrm{ml}$ showed no inhibition on the production of ten cytokines except for GM-CSF displaying a mild decrease (Fig. 3). Therefore, all the three tested immunosuppressants have their distinctive cytokine signatures, suggesting the possibility to evaluate the effect of individual immunosuppressants by cytokine signatures.

\section{Immunosuppressants synergistically and specifically influence cytokine profiles}

In clinical practice, combination treatment with different immunosuppressants is commonly employed in order to enhance the immunosuppressive effects while to minimize side or toxic effects. It is important to understand whether combination of individual immunosuppressants has synergistic effects on cytokine profiles and what the specific contribution of each immunosuppressant is in a combination protocol. To this end, we tested the combination of DEX $(1 \mu \mathrm{g} / \mathrm{ml}), \mathrm{CsA}(0.25 \mu \mathrm{g} / \mathrm{ml})$ and MPA $(10 \mu \mathrm{g} / \mathrm{ml})$ on cytokine profiles and compared their ef-
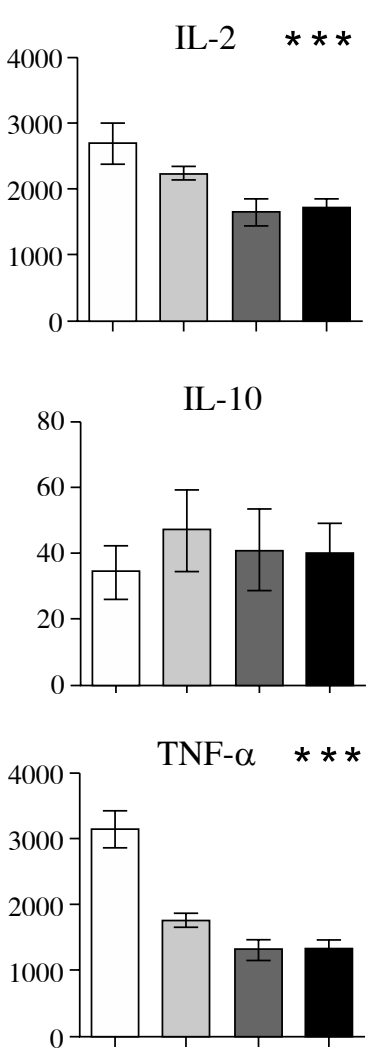
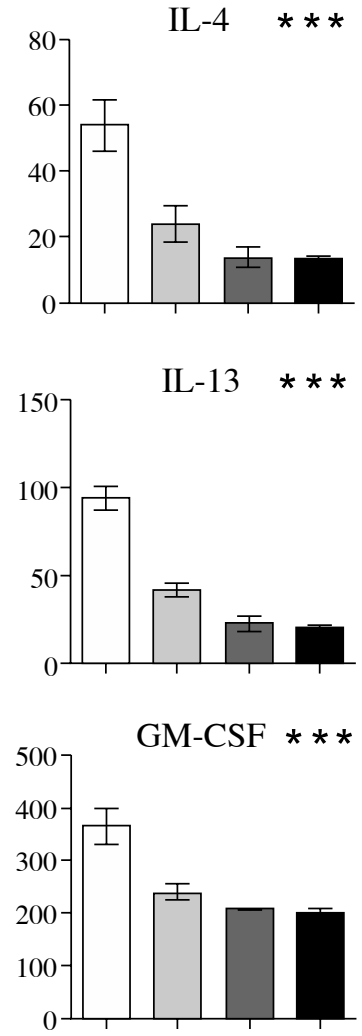
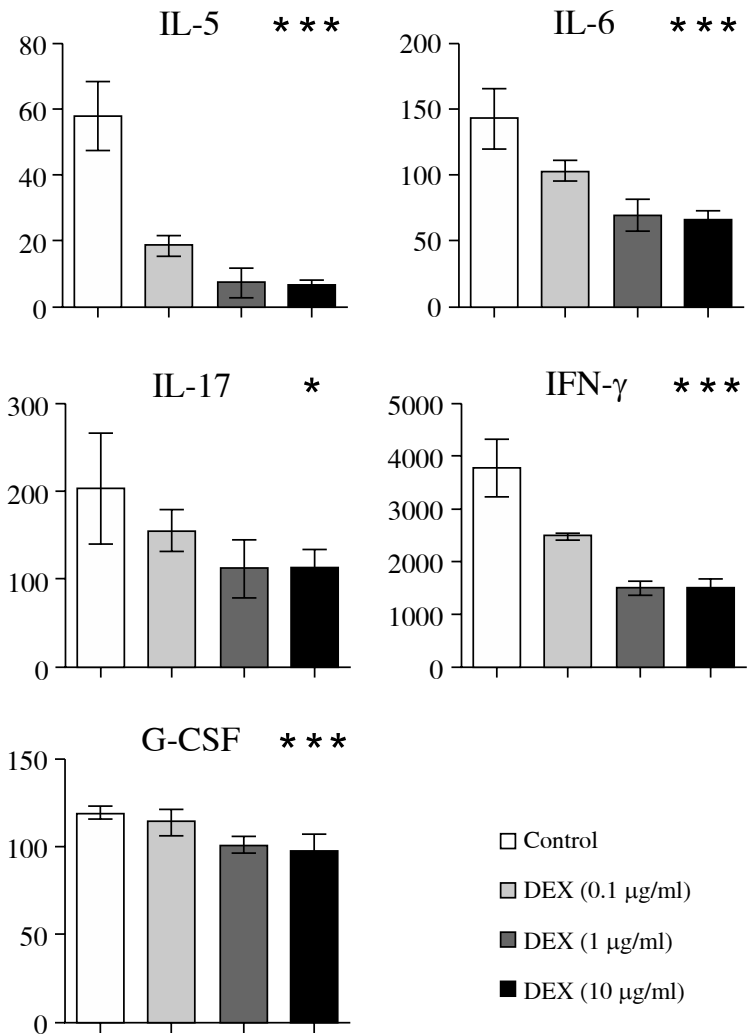

$\square$ Control

$\square \operatorname{DEX}(0.1 \mu \mathrm{g} / \mathrm{ml})$

$\square \operatorname{DEX}(1 \mu \mathrm{g} / \mathrm{ml})$

DEX $(10 \mu \mathrm{g} / \mathrm{ml})$

Fig. 1. DEX dose-dependently inhibits cytokine secretion. Whole blood $(200 \mu \mathrm{l})$ was treated with DEX $(0.1,1$ and $10 \mu \mathrm{g} / \mathrm{ml})$ for $6 \mathrm{~h}$ followed by stimulation with PMA $(0.15 \mu \mathrm{g} / \mathrm{ml})+\mathrm{IONO}(2.5 \mu \mathrm{g} / \mathrm{ml})$ for another $6 \mathrm{~h}$. Supernatants were collected for cytokine detection using the Bio-Plex system. Values are presented as Mean $\pm \operatorname{SD}(n=3)$ (linear trend test $\left.{ }^{*} p<0.05 ;{ }^{* * *} p<0.001\right)$ 

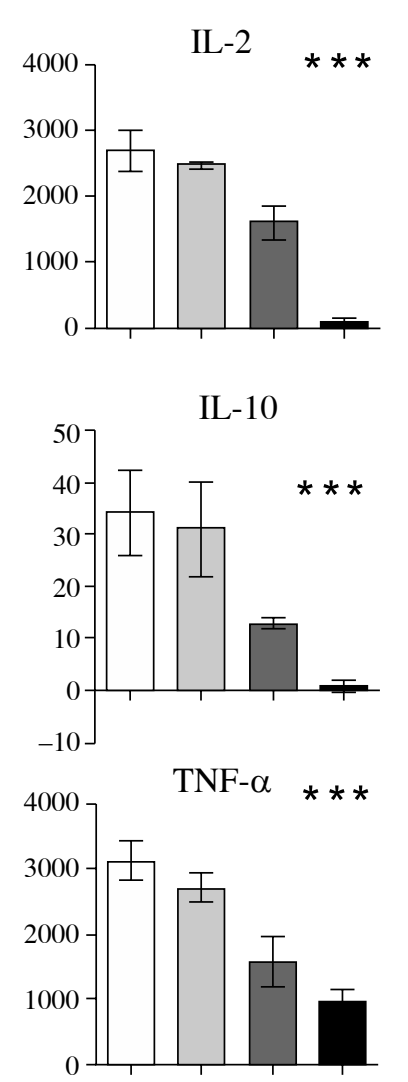
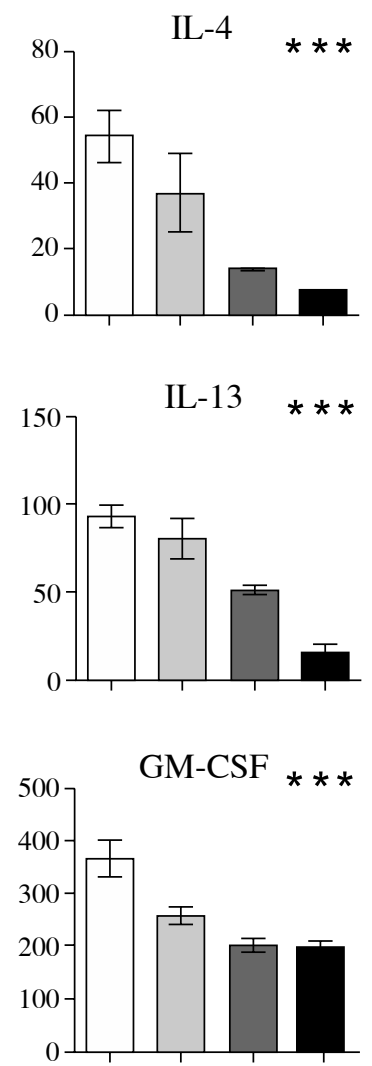
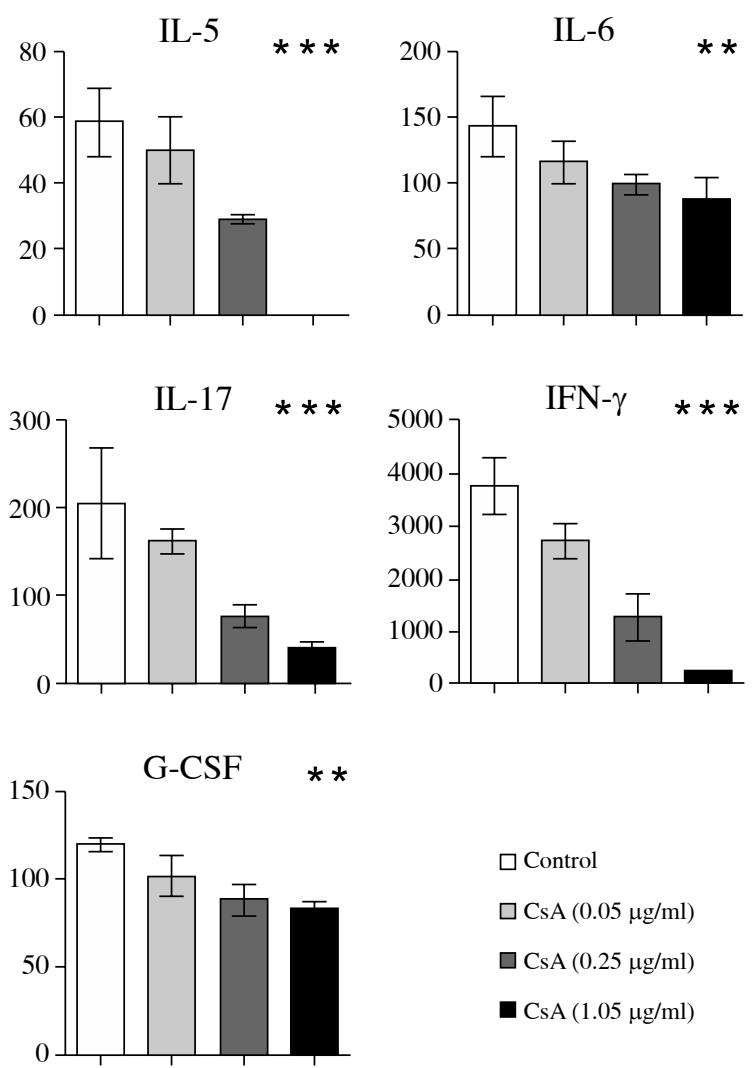

$\square$ Control

$\square \mathrm{CsA}(0.05 \mu \mathrm{g} / \mathrm{ml})$

$\square \mathrm{CsA}(0.25 \mu \mathrm{g} / \mathrm{ml})$

— $\mathrm{CsA}(1.05 \mu \mathrm{g} / \mathrm{ml})$

Fig. 2. CsA dose-dependently inhibits cytokine secretion. Whole blood $(200 \mu \mathrm{l})$ was treated with CsA $(0.05,0.25$ and $1.25 \mu \mathrm{g} / \mathrm{ml})$ for $6 \mathrm{~h}$ followed by stimulation with PMA $(0.15 \mu \mathrm{g} / \mathrm{ml})+\mathrm{IONO}(2.5 \mu \mathrm{g} / \mathrm{ml})$ for another $6 \mathrm{~h}$. Supernatants were collected for cytokine detection using the Bio-Plex system. Values are presented as mean $\pm \operatorname{SD}(n=3)$ (linear trend test $\left.{ }^{* *} p<0.01 ;{ }^{* * *} p<0.001\right)$

fects with no treatment control group, as well as groups with single treatment of DEX, MPA or CsA. The results showed that combination treatment inhibited IL-2, IL-4, IL-5, IL-6, IL-10, IL-13, IFN- $\gamma$, TNF- $\alpha$, GM-CSF and G-CSF as compared with a control group (Fig. 4). Importantly, the production of some cytokines like IL-2, IFN- $\gamma$ and TNF- $\alpha$ is decreased as compared with that of DEX, MPA or CsA single treatment, indicating that there were the synergistic effects of the three immunosuppressants on those cytokines. Other cytokines, such as IL-4, and GMCSF displayed a significantly decreased secretion as compared with control and MPA single treatment group, but their secretion was not different as compared with DEX or CsA single treatment groups, thus specifically reflecting the synergistic effects between DEX and CsA (Fig. 4). Furthermore, IL-5, IL-6 and IL-13 seem to specifically reflect the inhibitory effect by DEX, as its secretion in the combined treatment is only significantly decreased as compared with that in control, MPA or CsA single treatment groups, but not different from that in DEX single treatment (Fig. 4). Similarly, IL-10 and G-CSF may specifically reflect the effect of CsA, in that its level in combined treatment is only significantly decreased as com- pared with control, MPA or DEX single treatment groups, but not different from CsA single treatment group (Fig. 4). Therefore, whole blood cytokine profiles in combination treatment with multiple immunosuppressants can reflect not only the synergistic effects among different immunosuppressants, but also the specific effect of each immunosuppressant (Table 1).

\section{Discussion}

Immunosuppressive treatments are indispensable in autoimmune diseases as well as transplant rejections, but how to evaluate the effects of immunosuppressants is still a tough challenge $[1,24]$. Currently, physicians evaluate the immune status mainly through monitoring blood concentration of immunosuppressants, T lymphocyte subsets, blood biochemistry, biopsy findings and some clinical manifestations [4, 5, 25, 26]. However, therapeutic drug concentration monitoring can only provide blood levels of some drugs, but not their effects on the immune system. T lymphocyte subsets only reflect the number, but not the function of $\mathrm{T}$ cells, while biopsy is invasive that cannot be applied to the patients for periodical tests. As a result, 

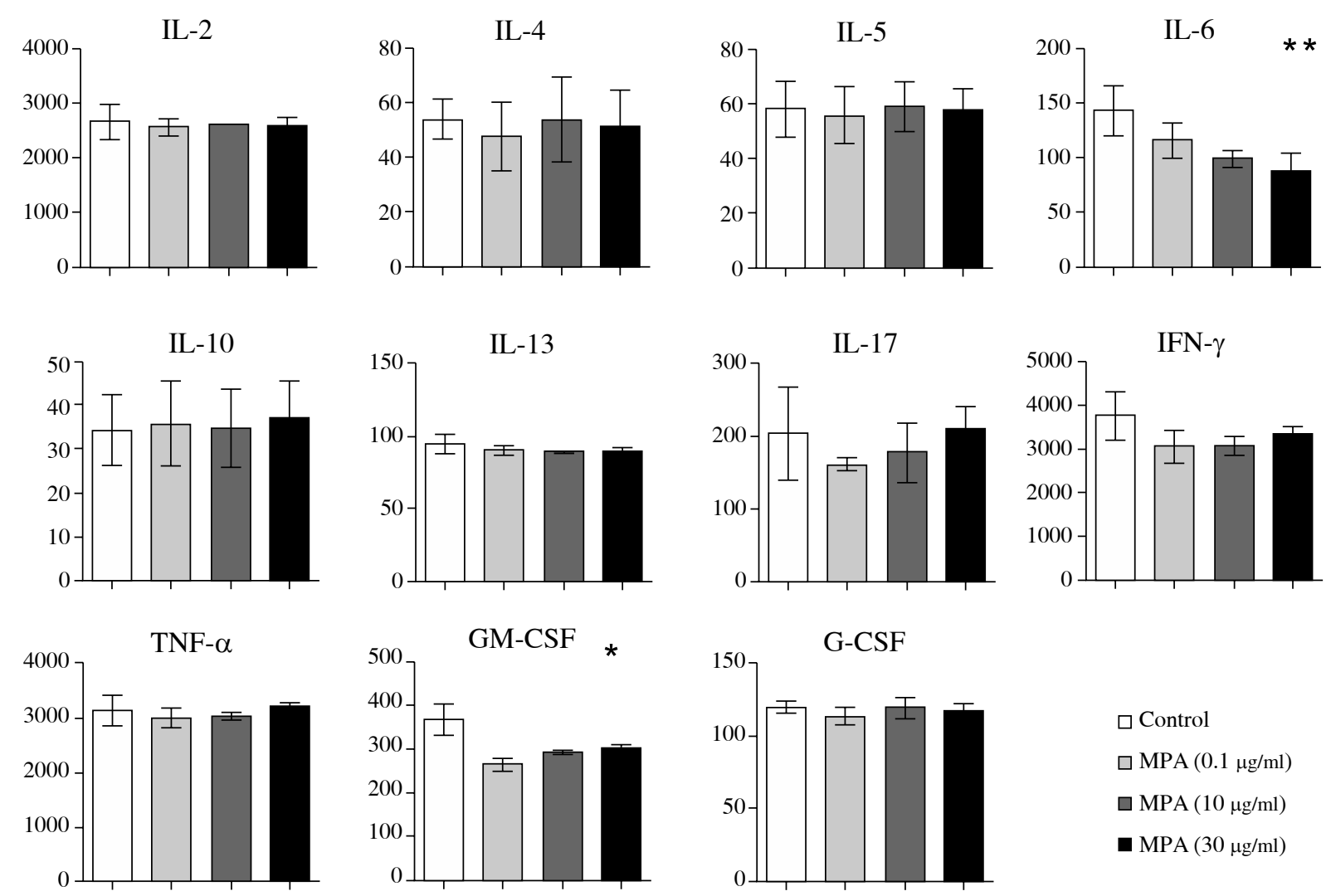

Fig. 3. MPA dose-dependently inhibits cytokine secretion. Whole blood $(200 \mu \mathrm{l})$ was treated with MPA $(1,10$ and 30 $\mu \mathrm{g} / \mathrm{ml})$ for $6 \mathrm{~h}$ followed by stimulation with PMA $(0.15 \mu \mathrm{g} / \mathrm{ml})+\mathrm{IONO}(2.5 \mu \mathrm{g} / \mathrm{ml})$ for another $6 \mathrm{~h}$. Supernatants were collected for cytokine detection using the Bio-Plex system. Values are presented as mean $\pm \operatorname{SD}(n=3)$ (linear trend test $\left.{ }^{*} p<0.05\right)$

all those currently available conventional methods cannot accurately and rapidly detect the immune status.

The following criteria should be considered in selecting a candidate method that deserves to monitor the function of immune cells in patients. First, it should not only reflect how much the immune system is suppressed, but also provide how the immune cells are specifically suppressed by each drug, enabling physicians to determine which drug should be adjusted for patients on multiple-drug treatments. Second, it should be highly accurate, easily replicable and finishable within very short periods so that the results can meet the immediate need in immunosuppressed patients, especially in patients suspected of over-immunosuppression induced infections. Third, a simple and non invasive sampling procedure is necessary that requires as little as possible human tissue in order that it is acceptable by patients requiring periodical tests of the immune function.

The development of Luminex technology makes it possible to simultaneously and accurately detect multiple cytokines in a tiny volume of blood, which may provide information on how much the immune system is suppressed and which immunosuppressant should be adjusted. To test this hypothesis, our initial attempt employed PHA to stimulate whole blood in vitro and investigated the effects of different immunosuppressants on the secretion of seventeen cytokines. We found that a $12 \mathrm{~h}$ stimulation of whole blood with PHA could maximize the secretion of most of the seventeen cytokines and different immunosuppressants displayed distinctive immunosuppressive cytokine profiles [12].

Although those results convey a promise for clinical application, there are other concerns. First, as nutrients in whole blood are limited, $12 \mathrm{~h}$ in vitro stimulation may consume out some essential factors and make immune cells dysfunctional. Second, long-term in vitro incubation also prevents its clinical application. Therefore, we set out to develop techniques to detect cytokine profiles with even shorter term in vitro stimulation. PMA/IONO activates PKC and increases intracellular $\mathrm{Ca}^{2+}$ concentration that is essential for T cell activation [20]. As PMA/IONO usually activates $\mathrm{T}$ cells more strongly and more rapidly by bypassing the membrane receptor necessary for mitogens, such as PHA, ConA and LPS, we investigated the cytokine profiles in PMA/IONO activated whole blood and the influence of immunosuppressants. We demonstrated that in PMA/IONO stimulated undiluted whole blood, DEX and CsA dose de- 

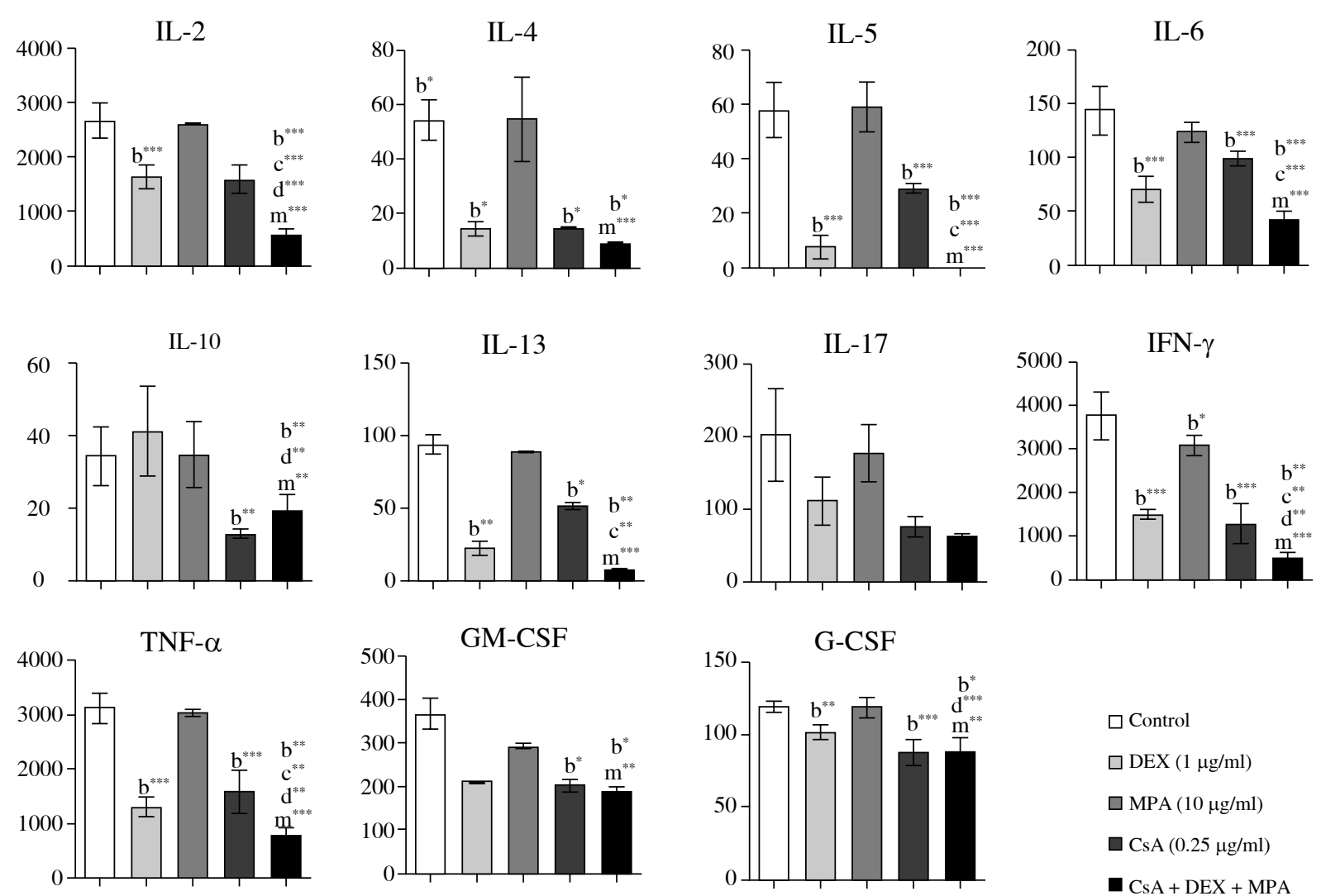

Fig. 4. Cytokine profiles reflect the synergistic and specific effects of immunosuppressants. Whole blood was treated with either DEX $(1 \mu \mathrm{g} / \mathrm{ml})$, CsA $(0.25 \mu \mathrm{g} / \mathrm{ml})$, MPA $(10 \mu \mathrm{g} / \mathrm{ml})$ alone or a combination of three drugs for $6 \mathrm{~h}$ followed by stimulation with PMA $(0.15 \mu \mathrm{g} / \mathrm{ml})+\operatorname{IONO}(2.5 \mu \mathrm{g} / \mathrm{ml})$ for another $6 \mathrm{~h}$. The results show that cytokine profiles can reflect the synergistic effects among immunosuppressants and distinctive effect of individual drug (b, c, d, m: the indicated groups were compared with a group of blank control, or single treatment groups with CsA, DEX or MPA, respectively). Values are presented as mean $\pm \operatorname{SD}\left(n=3\right.$, One-way ANOVA analysis $\left.{ }^{*} p<0.05 ;{ }^{* *} p<0.01 ;{ }^{* * *} p<0.001\right)$

pendently inhibited the secretion of some cytokines such as IL-2, IL-4, IL-5, IL-6, IL-13, IL-17, IFN- $\gamma$, TNF- $\alpha$, GM-CSF and G-CSF. Some cytokines like IL-4, IL-5, IL-13 seemed highly sensitive to DEX, while other cytokines, such as IL10 , is highly sensitive to CsA. On the contrary, MPA in three concentrations displayed no inhibitory effect except for GMCSF. The results revealed that different immunosuppressants have a distinctive effect on cytokine signatures, which points to potential application of this method to evaluate the efficacy of individual immunosuppressants. We also cultured undiluted whole blood for $6 \mathrm{~h}$ with a combination treatment of DEX, CsA and MPA followed by a stimulation with PMA/ IONO for another $6 \mathrm{~h}$, and compared the effect of the combination group with that of single drug treatments. In order to mimic the clinical situation, we chose the concentrations of immunosuppressants that were comparable to those in clinical transplant, with DEX $(1 \mu \mathrm{g} / \mathrm{ml}), \mathrm{CsA}(0.25 \mu \mathrm{g} / \mathrm{ml})$ and MPA $(10 \mu \mathrm{g} / \mathrm{ml})$, respectively. Indeed, the synergistic effects between drugs and specific effect of each drug can be reflect- ed by cytokine profiles. Most cytokines, such as IL-2, IFN- $\gamma$ and TNF- $\alpha$, were more profoundly inhibited in a combination treatment group than that in DEX, CsA, or MPA single treatment groups, indicating that the three drugs have a synergistic effect on those cytokines. More importantly, the results also showed that IL-4 and GM-CSF reflected the synergistic effect between DEX and CsA, while IL-5, IL-6 and IL-13 specifically reflected the effect of DEX. And IL-10, G-CSF mainly reflected the effect of CsA. These findings hold an important promise for patients on multiple drug immunosuppressive protocols. Clinically, a combination of several drugs is a common practice for the purpose of enhancing the immunosuppressive effect, while reducing the side or toxic effect of an individual drug. However, physicians are bewildered about which drug should be adjusted when patients are suspected of inadequate or over immunosuppression. The information from cytokine signatures may provide a valuable tool for physicians to adjust the type or dose of immunosuppressants. It should be stressed that cytokine profiles are dependent on 
Table 1. Cytokines reflect synergistic or specific effects of immunosuppressants

\begin{tabular}{|c|c|c|c|}
\hline Cytokines & $\begin{array}{c}\text { Comparisons between combined } \\
\text { treatment group (DEX + CsA + } \\
\text { MPA) with single drug treatment } \\
\text { groups }\end{array}$ & $\begin{array}{c}\text { Statistical } \\
\text { significance }\end{array}$ & $\begin{array}{l}\text { Immunosuppresive } \\
\text { significance }\end{array}$ \\
\hline $\begin{array}{l}\text { IL- } 2, \text { IFN- } \gamma \\
\text { TNF- } \alpha\end{array}$ & $\begin{array}{l}\text { Control } \\
\text { DEX } \\
\text { MPA } \\
\text { CsA }\end{array}$ & Yes & $\begin{array}{l}\text { Reflecting the synergistic effect of all three } \\
\text { immunosuppressants }\end{array}$ \\
\hline \multirow[t]{2}{*}{ IL-4, GM-CSF } & $\begin{array}{l}\text { Control } \\
\text { MPA }\end{array}$ & Yes & $\begin{array}{c}\text { Specifically reflects the synergistic effect of } \\
\text { DEX and CsA }\end{array}$ \\
\hline & $\begin{array}{l}\text { DEX } \\
\text { CsA }\end{array}$ & No & \\
\hline \multirow[t]{2}{*}{ IL-5, IL-6, IL-13 } & $\begin{array}{l}\text { Control } \\
\text { MPA } \\
\text { CsA }\end{array}$ & Yes & $\begin{array}{l}\text { Specifically reflects the synergistic effect of } \\
\text { DEX and CsA }\end{array}$ \\
\hline & DEX & No & \\
\hline \multirow[t]{2}{*}{ IL-10, G-CSF } & $\begin{array}{l}\text { Control } \\
\text { MPA } \\
\text { DEX }\end{array}$ & Yes & Specifically reflects the effect of CsA \\
\hline & CsA & No & \\
\hline
\end{tabular}

types of stimuli and in vitro stimulation time. As we have reported, in whole blood stimulated with PHA for $12 \mathrm{~h}$, DEX inhibited most cytokines, and FK506 and MPA only inhibited IL-2 and IL-13, whereas interestingly MPA increased one cytokine, IL-1 $\beta$ [12]. However, when whole blood was stimulated with PMA/IONO, MPA showed neither inhibition on the secretion of most cytokines nor enhancement on IL-1 $\beta$ production. Therefore, cytokine profiles are stimulation method dependent, suggesting a combination of several stimulation methods may provide more detailed information on immune cells and more reliable rationales for adjustment of immunosuppressive protocols.

In conclusion, a multi-plex based technique to simultaneously and quantitatively detect multiple cytokines in PMA/IONO stimulated undiluted whole blood may provide clinicians with a valuable tool for monitoring the function of immune cells, and for evaluating the synergistic effects between immunosuppressants and the specific effect of individual drugs. In addition, the short stimulation period may afford a rapid evaluation of patients' immune status, especially for those requiring an immediate readout of the immune system. The requirement of as little as several hundred microliter blood samples, the simple procedure and high reliability make it possible for physicians to test the immune status periodically and to adjust immunosuppression protocols before recurrence or infections develop. It is anticipated that this strategy may be applied to patients with autoimmune diseases, allergic disorders or transplant rejections that usually need intensive immunosuppressive treatments.
Since blood from healthy individuals were selected in our study, the cytokine profiles cannot be directly applied to patients with autoimmune diseases, allergic disorders or transplant rejections. Direct evidence from those patients is needed to validate the conception and techniques of applying cytokine profiles in the evaluation of the clinical immunosuppressive status. In fact, cytokine imbalance and cytokine scores have been associated with rheumatoid arthritis (RA)-related antibodies [27, 28]. Further investigations are necessary to determine whether cytokine profiles could reflect the immunosuppressive status in rheumatic or allergic patients undergoing immunosuppressant treatment and to develop more reliable cytokine profiles or scores for predicating their immunosuppressive status in patients with autoimmune diseases.

This work was supported by Grants from the $\mathrm{Na}$ tional Natural Science Foundation of China (30872312, U0832003), Guangdong Natural Science Foundation (5200513), Guangdong Natural Science Foundation (S2012010008725), Guangzhou Science and Technology Project (2007Z3-E0051), Medical research foundation in Guangdong province (B2012245), the Director Foundation of Third Affiliated Hospital of Southern Medical University (B2011004).

\section{References}

1. Ashton-Chess J, Giral M, Soulillou JP, Brouard S (2009): Can immune monitoring help to minimize immunosuppression in kidney transplantation? Transpl Int 22: 110-119. 
2. Chapman J (2008): Addressing the challenges for improving long-term outcomes in renal transplantation. Transplant Proc 40 (10 Suppl): S2-4.

3. Weimar W, Rischen-Vos J, de Kuiper P, et al. (2004): Tapering immunosuppression in recipients of living donor kidney transplants. Nephrol Dial Transplant 19 Suppl 4: iv61-63.

4. Kim DH, Kim JG, Sohn SK, et al. (2004): Clinical impact of early absolute lymphocyte count after allogeneic stem cell transplantation. Br J Haematol 125: 217-224.

5. Drasković-Pavlović B, Hrvacević R, Ignjatović Lj, et al. (2000): Importance of determining the absolute CD3+ lymphocyte count during induction therapy with antithymocyte globulin in kidney transplantation patients. Vojnosanit Pregl 57: 285-290.

6. Corris PA, Kirby JA (2005): A role for cytokine measurement in therapeutic monitoring of immunosuppressive drugs following lung transplantation. Clin Exp Immunol 139: 176-178.

7. Reddy M, Eirikis E, Davis C, et al. (2004): Comparative analysis of lymphocyte activation marker expression and cytokine secretion profile in stimulated human peripheral blood mononuclear cell cultures: an in vitro model to monitor cellular immune function. J Immunol Methods 293: 127-142.

8. Basak U, Mitra DK, Panigrahi A, et al. (2003): Clinical relevance of monitoring cytokine production following living donor renal transplantation. Transplant Proc 35: 404-406.

9. Vignali DA (2000): Multiplexed particle-based flow cytometric assays. J Immunol Methods 243: 243-255.

10. Dupont NC, Wang K, Wadhwa PD, et al. (2005): Validation and comparison of luminex multiplex cytokine analysis kits with ELISA: determinations of a panel of nine cytokines in clinical sample culture supernatants. J Reprod Immunol 66: 175-191.

11. Lagrelius M, Jones P, Franck K, Gaines H (2006): Cytokine detection by multiplex technology useful for assessing antigen specific cytokine profiles and kinetics in whole blood cultured up to seven days. Cytokine 33: 156-165.

12. Liu Z, Yuan X, Luo Y, et al. (2009): Evaluating the effects of immunosuppressants on human immunity using cytokine profiles of whole blood. Cytokine 45: 141-147.

13. Riebe C, Pries R, Kemkers A, Wollenberg B (2007): Increased cytokine secretion in head and neck cancer upon p38 mitogen-activated protein kinase activation. Int J Mol Med 20: 883-887.

14. Langer S, Langnickel D, Enghard P, et al. (2007): The systemic and SmD183-119-autoantigen-specific cytokine memory of Th cells in SLE patients. Rheumatology (Oxford) 46: 238-245.

15. Cornejo-Garcia JA, Fernandez TD, Torres MJ, et al. (2007): Differential cytokine and transcription factor expression in patients with allergic reactions to drugs. Allergy 62: 1429-1438.

16. Shahneh FZ, Babalo Z, Baradaran B, Sepehr KS (2012): Insights into Behçet's disease. Postep Derm Alergol 29: 6: 461-466

17. Aleksandra Dańczak-Pazdrowska A (2012): Place of methotrexate in the treatment of psoriasis in the era of biologic agents. Postep Derm Alergol 2012; 29: 182-188.

18. Smits HH, Grünberg K, Derijk RH, et al. (1998): Cytokine release and its modulation by dexamethasone in whole blood following exercise. Clin Exp Immunol 111: 463-468.

19. Hölschermann H, Dürfeld F, Maus U, et al. (1996): Cyclosporine $\mathrm{A}$ inhibits tissue factor expression in monocytes/macrophages. Blood 88: 3837-3845.
20. Laurent AF, Dumont S, Poindron P, Muller CD (1996): Mycophenolic acid suppresses protein N-linked glycosylation in human monocytes and their adhesion to endothelial cells and to some substrates. Exp Hematol 24: 59-67.

21. Petrovsky N, Harrison LC (1995): Cytokine-based human whole blood assay for the detection of antigen-reactive T cells. J Immunol Methods 186: 37-46.

22. van Crevel R, van der Ven-Jongekrijg J, Netea MG (1999): Disease-specific ex vivo stimulation of whole blood for cytokine production: applications in the study of tuberculosis. J Immunol Methods 222: 145-153.

23. Chatila T, Silverman L, Miller R, Geha R (1989): Mechanisms of $\mathrm{T}$ cell activation by the calcium ionophore ionomycin. J Immunol 143: 1283-1289.

24. Hariharan S, Stablein DE (2005): Improvements in long-term renal transplant graft survival. Am J Transplant 5: 630-631; author reply 632-633.

25. Rodrigo E, de Cos MA, Fernandez-Fresnedo G, et al. (2005): Higher initial tacrolimus blood levels and concentration-dose ratios in kidney transplant recipients who develop diabetes mellitus. Transplant Proc 37: 3819-3820.

26. Jorga A, Holt DW, Yaqoob M, et al. (2004): A survey to determine the blood concentration of cyclosporine 2 hours postdose in stable renal transplant patients. Transplant Proc 36: 3239-3241.

27. Nankivell BJ, Chapman JR (2006): The significance of subclinical rejection and the value of protocol biopsies. Am J Transplant 6: 2006-2012.

28. Hughes-Austin JM, Deane KD, Derber LA, et al. (2013): Multiple cytokines and chemokines are associated with rheumatoid arthritis-related autoimmunity in first-degree relatives without rheumatoid arthritis: Studies of the Aetiology of Rheumatoid Arthritis (SERA). Ann Rheum Dis 72: 901-907. 